\title{
A Miniaturized Broadband and High Gain Planar Vivaldi Antenna for Future Wireless Communication Applications
}

\author{
Permanand Soothar $\mathbb{D}^{1,}{ }^{1,2}$ Hao Wang $\mathbb{D}^{1},{ }^{1}$ Chunyan $X u^{1}$ Yu Quan, ${ }^{1}$ Zaheer Ahmed Dayo, ${ }^{3,4}$ \\ Muhammad Aamir, ${ }^{4}$ and Badar Muneer ${ }^{2}$ \\ ${ }^{1}$ School of Electronic and Optical Engineering, Nanjing University of Science and Technology (NJUST), Nanjing 210094, China \\ ${ }^{2}$ Department of Electronic and Telecommunication Engineering, Mehran University of Engineering and Technology (MUET), \\ Jamshoro, Sindh 76062, Pakistan \\ ${ }^{3}$ College of Electronic and Information Engineering, Nanjing University of Aeronautics and Astronautics (NUAA), \\ Nanjing 211106, China \\ ${ }^{4}$ Department of Computer Science, Huanggang Normal University, Huangzhou, Hubei 438000, China
}

Correspondence should be addressed to Permanand Soothar; permanand.soothar@njust.edu.cn and Hao Wang; haowang@njust.edu.cn

Received 2 April 2021; Revised 5 July 2021; Accepted 16 July 2021; Published 6 August 2021

Academic Editor: Giuseppina Monti

Copyright $\odot 2021$ Permanand Soothar et al. This is an open access article distributed under the Creative Commons Attribution License, which permits unrestricted use, distribution, and reproduction in any medium, provided the original work is properly cited.

\begin{abstract}
This paper presents a new miniaturized planar Vivaldi antenna (PVA) design. The proposed antenna structure consists of an aperture tapered profile and cavity stub fed with a simple $50 \Omega$ strip line feeding network. The designed PVA offers versatile advantages, including the miniaturized size and simple design, and exhibited an outstanding performance compared to the latest reported literature. The antenna occupies a minimal space with an electrical size of $0.92 \lambda_{0} \times 0.64 \lambda_{0} \times 0.03 \lambda_{0}$. The antenna achieves an excellent relative impedance bandwidth $117.25 \%$ at $10 \mathrm{~dB}$ return loss, peak realized gain of $10.9 \mathrm{dBi}$, and an excellent radiation efficiency of $95 \%$ at the specific resonances. The antenna's optimal features, that is, broadband, high gain, and radiation efficiency, are achieved with efficient grooves based approach. Besides, the proposed antenna results are also analyzed in the time domain, which shows the excellent group delay performance $<2 \mathrm{~ns}$ in the operational band. The proposed antenna exhibited a stable farfield radiation pattern in orthogonal planes and strong distribution of current at multiple resonances. Simulation and the measured result show a good agreement. The proposed antenna has achieved optimal performance and is suitable for future wireless communication applications.
\end{abstract}

\section{Introduction}

In modern wireless communication systems, the implementation and demand of a high data rate transmission scheme are increasing rapidly [1]. The antenna systems, which may exhibit optimal performance and cover multiple wireless communication services, are very suitable for modern communication systems. Therefore, in order to fulfill the demand, compact, high gain, wideband, and radiation efficient PVA are required. Such antennas are an essential component of the modern communication system and acquired substantial consideration due to best performance features, that is, broadband, high gain, radiation efficiency, and stable far-field patterns, with advantages of low cost, low profile, and minimal size [2].

Currently, the PVA is a good choice for future wireless communication applications, including ultrawideband (UWB) spectrum [3, 4], intersatellite communication [5], medical imaging [6], notch band [7], wide beam scanning phased array [8], ground-penetrating radar (GPR) system [9], and radar (radio detection and ranging) [10]. The PVA has demonstrated broad impedance bandwidth (BW), high gain, good radiation efficiency, and wide beam pattern. Generally, it contains a strip line or microstrip feedline transition with radial cavity stub. The radiating parts of the antenna were erected exponentially, elliptically, linear 
curvatures, and constant width slots [11]. The main concerns for active researchers related to the antenna designing field are mainly the antenna's large electrical and physical size, narrow impedance $\mathrm{BW}$, moderate gain, and low radiation efficiency. Hence, the prime focus of the antenna designers is to refine the main aspects of the antenna structures, such as wide impedance BW, compact size, gain, radiation efficiency performance, and stable far-field radiation features [12].

In the last decade, different structures of the compact planar antennas were investigated to enhance the antenna impedance $\mathrm{BW}$, gain performance, and radiation characteristics [13]. However, very few antenna designs have a compact size with a tapered profile and can attain the antenna's optimal key characteristics. In the literature, various antenna geometries, such as slits, tapered slot radiator, and flared transition with modified cavity stubs [14-17] have been reported. Also, several designs based on different slot shapes [18-20] were suggested to achieve the required gain, acceptable $\mathrm{BW}$, radiation efficiency, and perfect impedance matching. The reported antennas consist of intricate structures and exhibited a satisfactory performance in terms of BW, peak gain, and radiation efficiency. The coplanar waveguide (CPW) fed bowtie slot antenna with large size achieved triple-band response reported in [21]. Awl et al. proposed microstrip antenna for $\mathrm{C}, \mathrm{X}$, and $\mathrm{Ku}$ band applications with an electrical size of $0.687 \lambda_{0} \times 0.492 \lambda_{0} \times 0.1038 \lambda_{0}$ at the $9.8 \mathrm{GHz}$ [22]. The presented antenna design comprised of a semitriangular patch shape with a CPW feedline and attained $107 \%$ fractional BW with $5.3 \mathrm{dBi}$ realized gain performance. Besides, the compact size linear tapered slot antenna design with tilt grooves approach is demonstrated in [23]. The designed antenna achieved an impedance BW of $15.5 \mathrm{GHz}$ with broad beam characteristics. A tapered slot antenna (TSA) employing a folded form technique achieved enhanced impedance BW and gain [24]. The proposed antenna design was complex and attained acceptable gain and broad impedance $\mathrm{BW}$ with a large electrical size of $4.0 \lambda_{0} \times 2.4 \lambda_{0} \times 0.032 \lambda_{0}$.

Another work on TSA was proposed for imaging applications with the size of $2.09 \lambda_{0} \times 1.566 \lambda_{0} \times 0.034 \lambda_{0}$ [25]. The antenna achieved $77 \%$ BW and has a larger size. The authors proposed antenna array and obtained $\sim 55 \%$ broad BW, and excellent peak realized gain with antenna size of $1.8 \lambda_{0} \times 1.38 \lambda_{0} \times 0.024 \lambda_{0}$ [26]. The substrate integrated waveguide (SIW) based new shaped antenna with broadband impedance BW is reported in [27]. However, the developed antennas reported in the literature were larger in size and employed a high fabrication process and complicated assembly. Another work on high gain bowtie slot antenna achieved the multiple frequency bands [28]. The proposed structure was simple and printed on FR4 substrate. The authors presented wideband loaded linear TSA with broad beam width [29]. Besides, the Chang team designed an antenna on FR4 substrate with a larger dimension of $1.465 \lambda_{0} \times 0.847 \lambda_{0} \times 0.02 \lambda_{0}$ and covered $82.2 \%$ relative impedance BW. The reported antenna comprises three types of inverted $\mathbb{I I}$ (omega-shaped) loaded slots and has a complex structure with large size. Krishna et al. [30] developed the antenna for S, C, X, and Ku band applications with a compact size of $2.0 \lambda_{0} \times 2.5 \lambda_{0} \times 0.067 \lambda_{0}$ and obtained the impedance $\mathrm{BW}$ of $15 \mathrm{GHz}$ with a peak realized gain of $7.0 \mathrm{dBi}$. However, the work presented in [30] occupied large antenna size with dual exponentially slotted, resulting in computational complexity. A compact wideband CPW-fed taper-shaped monopole antenna with an L-slot has been investigated in [31]. The antenna was realized on FR4 substrate with compact dimensions of $0.395 \lambda_{0} \times 0.355 \lambda_{0} \times 0.0315 \lambda_{0}$ and obtained the narrow BW performance ranging from 3.8 to $8 \mathrm{GHz}$ with a modest gain of $3.4 \mathrm{dBi}$. Another high gain CPW-fed antenna is proposed in [32]. The authors achieved good performance with a large antenna size.

In this paper, a new miniaturized structure of PVA is designed, simulated, and fabricated. The proposed tapered structure is erected with alternate grooves based technique that obtained the wide impedance BW, high gain, excellent radiation efficiency, and stable far-field radiation characteristics. The proposed antenna has the miniaturized size of $0.92 \lambda_{0} \times 0.64 \lambda_{0}$ printed on a Teflon ${ }^{\mathrm{TM}}$ laminate with a thickness of $0.03 \lambda_{0}$. A comparison with the recent state-ofthe-art work is provided. The proposed model achieves the relative $\mathrm{BW}$ of $117.25 \%$ with $\left|\mathrm{S}_{11}\right|$ better than $10 \mathrm{~dB}$, the peak realized gain of $10.9 \mathrm{dBi}$, the excellent radiation efficiency of $95 \%$, good performance of group delay $<2 \mathrm{~ns}$, stable far-field radiation pattern in E- and H-planes, and consistent strong current distribution at multiple resonances.

The main contribution of this paper is as follows:

(i) The designed PVA is compact in size, overcomes the simulation and geometrical complexity, and achieves optimal performance

(ii) A robust grooves based method is proposed which reduces the design and fabrication complexity of the antenna

(iii) The antenna achieves an excellent relative BW of $117.25 \%$, a high realized gain of $10.9 \mathrm{dBi}$, and excellent radiation efficiency of $95 \%$

(iv) The proposed antenna results are validated in the time domain, that is, group delay, which shows the excellent performance $<2 \mathrm{~ns}$ across the operable frequency span

(v) The proposed antenna exhibits the optimal performance features, and their comparison is provided with recently reported literature (comparison presented in Table 1), which shows the clear advantages

The rest of the article is organized as follows: Section 2 presents the suggested design material, antenna arrangement, and proposed antenna model strategy. The impact of different variable and sketches of surface current distribution is also provided in this section. Section 3 offers the analysis of the simulated and measured results of the proposed antenna. The peak realized gain, radiation efficiency, group delay, and far-field radiation pattern along the standard planes are analyzed and discussed in this section. Finally, the conclusion of the study is explained in Section 4. 
TABLE 1: Comparison of different antenna key features.

\begin{tabular}{|c|c|c|c|c|c|c|}
\hline Ref. & Profile & $\begin{array}{c}\text { Antenna dimensions } \\
L \times W \times H\left(\lambda_{0}\right)\end{array}$ & $\begin{array}{c}\text { Whole dimensions } \\
\left(\mathrm{mm}^{2}\right)\end{array}$ & $\begin{array}{c}\text { Fractional bandwidth } \\
(\%)\end{array}$ & $\begin{array}{c}\text { Max. gain } \\
(\mathrm{dBi})\end{array}$ & $\begin{array}{c}\text { Radiation efficiency } \\
(\%)\end{array}$ \\
\hline This work & Linearly & $0.92 \times 0.64 \times 0.03$ & 248.535 & 117.25 & 10.9 & 95 \\
\hline Awl et al. [22] & $\begin{array}{c}\text { Semitriangular } \\
\text { patch }\end{array}$ & $0.687 \times 0.492 \times 0.1038$ & 315 & 107.69 & 5.3 & US \\
\hline Zhang et al. [23] & Linearly & $0.735 \times 0.965 \times 0.028$ & 336 & 112.72 & US & US \\
\hline Arezoomand et al. & Linearly & $4.0 \times 2.4 \times 0.032$ & 6000 & 100 & 15 & 89 \\
\hline Jiang et al. [25] & Exponential & $2.09 \times 1.566 \times 0.034$ & 1728 & 76.92 & 11.8 & US \\
\hline Soothar et al. [26] & Linearly & $1.8 \times 1.38 \times 0.024$ & 6210 & 66.66 & 10.75 & 90 \\
\hline Wu et al. [27] & Exponential & $1.28 \times 1.46 \times 0.02$ & 2574 & 60.86 & 8.7 & US \\
\hline Chang et al. [29] & Linearly & $1.465 \times 0.847 \times 0.02$ & 2082 & 82.19 & US & US \\
\hline Krishna et al. [30] & Exponential & $2.0 \times 2.5 \times 0.067$ & 2880 & 120 & 7 & US \\
\hline Naji [31] & Taper shaped & $0.395 \times 0.355 \times 0.0315$ & 360 & 71.18 & 3.4 & 95 \\
\hline
\end{tabular}

US: unspecified.

\section{The Proposed Antenna Arrangement and Geometry}

In this section, we discuss the designed antenna layout and simulation results analysis. The proposed prototype is engraved on Teflon ${ }^{\mathrm{TM}}$ laminate with relative permittivity of 2.1 and loss tangent of 0.001 . It consists of a top metal plate etched with tapered lines and the radial cavity stub. Moreover, a strip line feeding network with a fan-made stub is used to connect the $50 \Omega$ SubMiniature version A (SMA) connector. The feedline is placed on the bottom of the substrate. A high-frequency structure simulator (HFSS) $\mathrm{V}-17.1$ is used to design the proposed structure. The compact antenna model aims to produce a broad impedance BW, high gain and radiation efficiency, stable far-field patterns, and strong current distribution at multiple resonances.

Figure 1 shows the three-dimensional (3D) view of the designed and simulated antenna model, consisting of a dielectric substrate, metal plate, and strip line feedline framework. The metal plate is etched with tapered lines, slots, and the radial cavity stub, where the strip line feed network is connected with a balun cavity stub placed on bottom of the substrate. The opening tapered profile depends on aperture $H$, and its width must be greater than half of the free-space wavelength. A slot line is engraved on the metal ground plate with a radius $\left(r_{1}\right)$ and a rectangle slot $\left(L_{1 \mathrm{SL}}\right)$ tapered profile depicted in Figure 2.

The parallel rectangle slot line segment is used to perform the coupling. Besides, the gradual exponential profile radiates the free space in the steady opening part from the inevitable electromagnetic waves to the tapered aperture $(H)$, which primarily marks the transmission of electromagnetic waves. The gradual exponential profile radiates the free space in the steady opening part from the inevitable electromagnetic wave to the tapered aperture $(H)$.

In the metal plate, two grooves are introduced with $0.3 \mathrm{~mm}$ width at the opening profile affecting the lower operating band ranging from 6 to $7 \mathrm{GHz}$. However, the truncated line is adopted at the $100 \Omega$ transmission line to achieve the load terminal matching equal to the ground terminal.

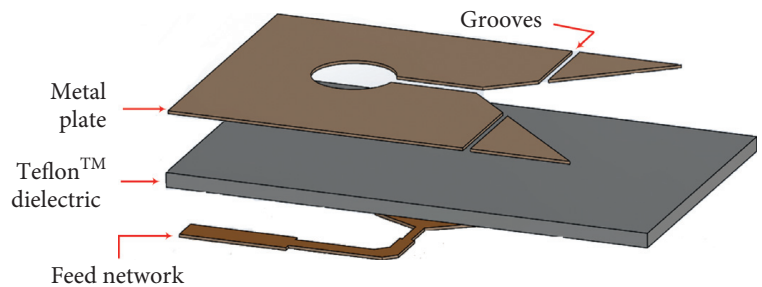

FIgURE 1: A 3D view of the proposed antenna structure.

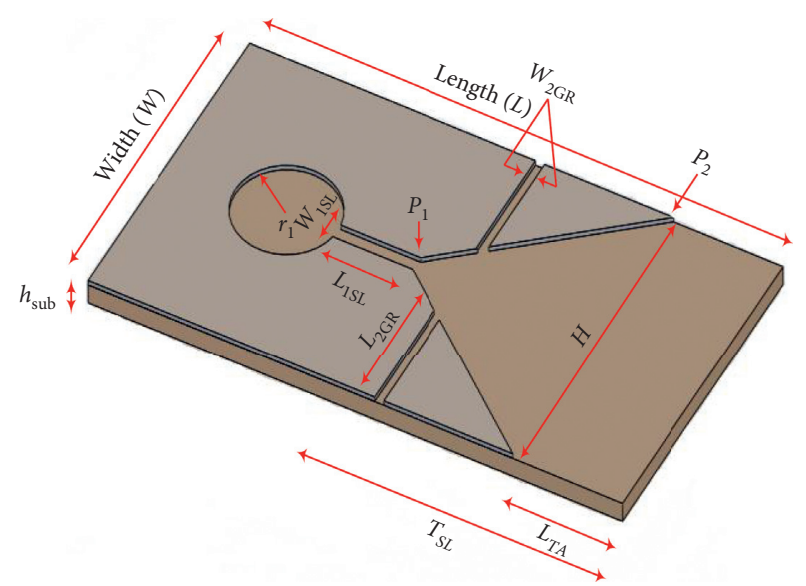

FIGURE 2: The 3D-geometrical arrangement of the proposed planar Vivaldi antenna.

The linear expression of the exponential tapered profile curve is determined by

$$
y=c_{1} e^{R x}+c_{2}
$$

where

$$
\begin{aligned}
& c_{1}=\frac{y_{2}-y_{1}}{e^{R x_{2}}-e^{R x_{1}}}, \\
& c_{2}=\frac{y_{1} e^{R x_{2}}-y_{2} e^{R x_{1}}}{e^{R x_{2}}-e^{R x_{1}}} .
\end{aligned}
$$

Two conical points can calculate the linearly exponential tapered profile $P_{1}\left(x_{1}, y_{1}\right)$ and $P_{2}\left(x_{2}, y_{2}\right)$ and $R$ is specified 
by the opening rate of the exponential factor. The parameters $c_{1}$ and $c_{2}$ are determined by the constants of coordinates of the opening rate. Besides, the slit line transition is indicated by the $\left(W_{1 \mathrm{SL}}\right)$ and $\left(W_{2 \mathrm{GR}}\right)$ and strip line transition is stated with $W_{3 \mathrm{FL}}, W_{4 \mathrm{FL}}$, and $W_{5 \mathrm{FL}}$. Moreover, the taper line $T_{\mathrm{SL}}$ is determined as $\left(x_{2}-x_{1}\right)$ and the height of the aperture section " $H$ " is $2\left(y_{2}-y_{1}\right)+W_{1 \mathrm{SL}}$. When the opening rate $R$ is approaching zero, the exponential taper results $s_{0}=\left(y_{2}-\right.$ $\left.y_{1} / x_{2}-x_{1}\right)$ provide the tapered slope. The taper slope " $\mathrm{s}$ " changes continuously from $s_{1}$ to $s_{2}$ for the exponential taper defined by equation (1), where $s_{1}$ and $s_{2}$ are the taper slopes at $x=x_{1}$ and $x=x_{2}$ and $s_{1}<s<s_{2}$ for $R>0$. The angle of the taper flare is characterized by $\alpha=\tan ^{-1} s$ that parameters are interrelated to $W_{1 \mathrm{SL}}, T_{\mathrm{SL}}, H$, and opening rate $R$.

The EM waves uncouple from the tapered profile, and the structure radiates into free space from the laminate end. For the TSA to radiate appropriately, it has to behave as a surface-wave antenna. To achieve this, the effective dielectric thickness $t_{\mathrm{eff}}=\left(\sqrt{\varepsilon_{r}}-1\right) t$, where $t$ shows the thickness parameter of actual laminate must meet the following requirements [33]:

$$
0.005 \lambda_{0}<t_{\text {eff }}<0.03 \lambda_{0}
$$

where $\lambda_{0}$ is the free space wavelength at the center frequency. The thinner the dielectric substrate, the wider the width while the beam width will break if the substrate is thicker. Furthermore, in many wireless applications, alternate fed network performance requires a narrower BW [34]. As a result, different feed networks such as microstrip line, circular cavity stub, and strip line exist. In the proposed design, the strip line feed system is excited through a $50 \Omega$ SMA connector containing the balun stub transformer section, as illustrated in Figure 3. The proposed antenna structure provides a broad impedance $\mathrm{BW}$ of $6-23 \mathrm{GHz}$ with good radiation characteristics.

Geometrically optimized values of the proposed antenna are illustrated in Table 2.

\subsection{Variation in Slot Line Width $\left(W_{1 S L}\right)$ and Groove Width} $\left(W_{2 G R}\right)$. This section explains the impedance matching of the developed antenna model. The return loss $\left|S_{11}\right|$ plot with various values is illustrated in Figures 4(a) and 4(b). It is observed that the simulated result resonances obtained inclusive impedance BW performance. The values range from $0.5 \mathrm{~mm}$ to $0.8 \mathrm{~mm}$; the width of the slot line $\left(W_{1 \mathrm{SL}}\right)$ transition is varied. The best result for impedance matching is obtained at the value of $0.7 \mathrm{~mm}$, as shown in Figure 4(a). The combination of radial cavity stub and tapered profile is used to achieve the antenna parameter accuracy. By applying the variation from $0.1 \mathrm{~mm}$ to $0.4 \mathrm{~mm}$ of the groove width $\left(W_{2 \mathrm{GR}}\right)$, the optimum results have been obtained at the values of $0.3 \mathrm{~mm}$, as illustrated in Figure 4(b).

2.2. Current Distribution. Figure 5 shows the surface current distribution of the proposed antenna. It can be analyzed that the strong current density appears at the higher frequency of the operable BW. Figure 5(a) shows the surface current

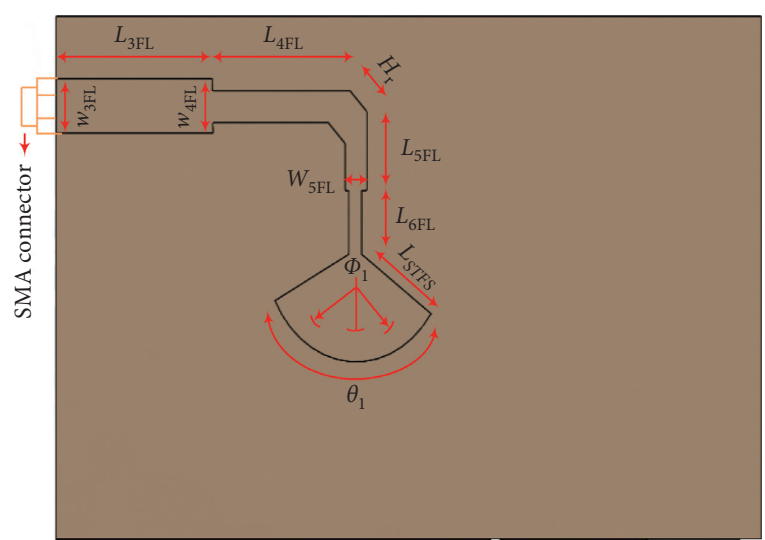

FIgURE 3: Geometrical feeding network of the proposed antenna.

TABle 2: Assigned geometrical variables along with optimum values $(\mathrm{mm})$.

\begin{tabular}{lcccc}
\hline Parameters & $W_{1 \mathrm{SL}}$ & $W_{2 \mathrm{GR}}$ & $W_{3 \mathrm{FL}}$ & $W_{4 \mathrm{FL}}$ \\
Optimized value & 0.7 & 0.3 & 1.55 & 0.55 \\
Parameters & $W_{5 \mathrm{FL}}$ & $H_{\mathrm{r}}$ & $\Phi_{1}$ & $\Theta_{1}$ \\
Optimized value & 0.5 & 0.5 & $120^{\circ}$ & $40^{\circ}$ \\
Parameters & $r_{1}$ & $L_{1 \mathrm{SL}}$ & $L_{2 \mathrm{GR}}$ & $T_{\mathrm{SL}}$ \\
Optimized value & 1.5 & 2.85 & 3.68 & 11 \\
Parameters & $L_{\mathrm{TA}}$ & $L_{\mathrm{STFS}}$ & $L_{3 \mathrm{FL}}$ & $L_{4 \mathrm{FL}}$ \\
Optimized value & 2.76 & 3 & 3.55 & 2.55 \\
Parameters & $L_{5 \mathrm{FL}}$ & $L_{6 \mathrm{FL}}$ & $h_{\text {sub }}$ & $W$ \\
Optimized value & 1.55 & 2 & 0.6 & 13.15 \\
Parameters & $L$ & & & \\
Optimized value & 18.9 & & & \\
\hline
\end{tabular}

intensity at the first resonance of $6.6 \mathrm{GHz}$. The feed line is excited by $50 \Omega$ SMA connector at the bottom of the substrate laminate and transited due to radial cavity and the taper profile as can be seen from Figure 5(a). Moreover, the second resonance point indicated at $12.3 \mathrm{GHz}$ shows the high current intensity to the slot line and the grooves to the taper lines as illustrated in Figure 5(b). Thus, the current intensity is very high and is concentrated at the high frequency of $20.2 \mathrm{GHz}$ and $22.3 \mathrm{GHz}$, as shown in Figures 5(c) and $5(\mathrm{~d})$.

\section{Simulated and Tested Results}

3.1. Return Loss $\left|S_{11}\right|$. S-parameters, peak realized gain, and radiation characteristics are the critical antenna output indexes. For an optimal antenna design and its high efficiency, these interdependent metrics need to be balanced. $S$-parameter of the fabricated structure was measured with a calibrated Agilent vector network analyzer N5244A. The simulated and measured results of return loss $\left|S_{11}\right|$ are illustrated in Figure 6. The simulated results show multiple resonances, indicating that the proposed antenna has achieved comprehensive impedance BW performance. Although with a slight change in frequency, the simulated results (black and red curve) have several resonances observed at $6.6 \mathrm{GHz}, 12.3 \mathrm{GHz}, 20.2 \mathrm{GHz}$, and $22.3 \mathrm{GHz}$.

Moreover, a small variation in calculated and simulated outcomes can be seen in Figure 6. These inaccuracies are primarily due to assembly error and experimental 


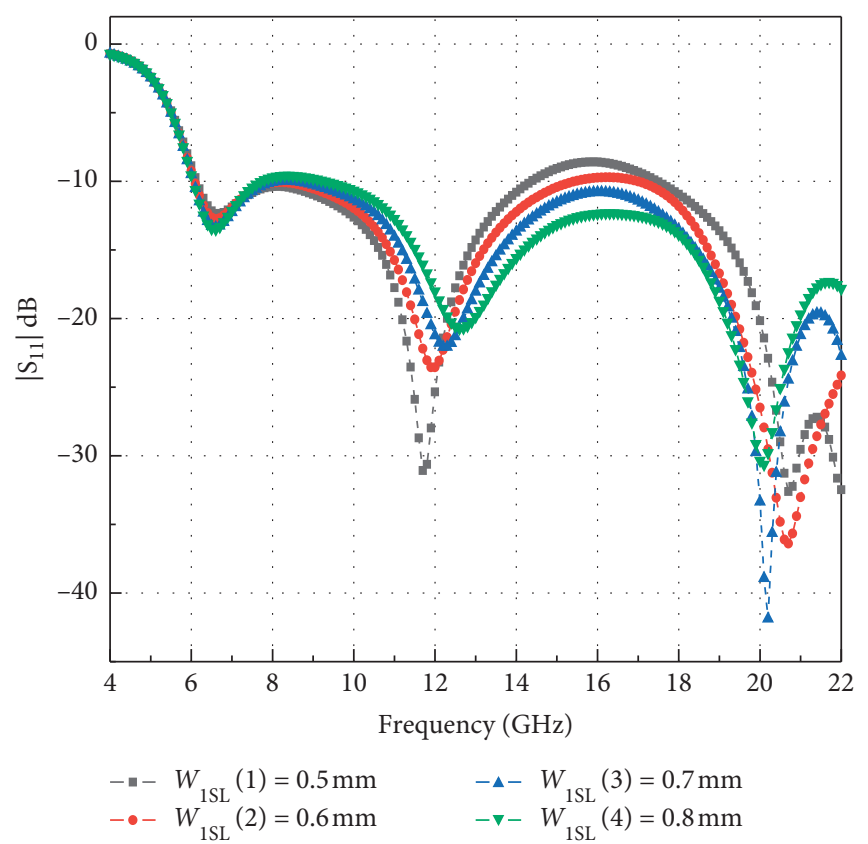

(a)

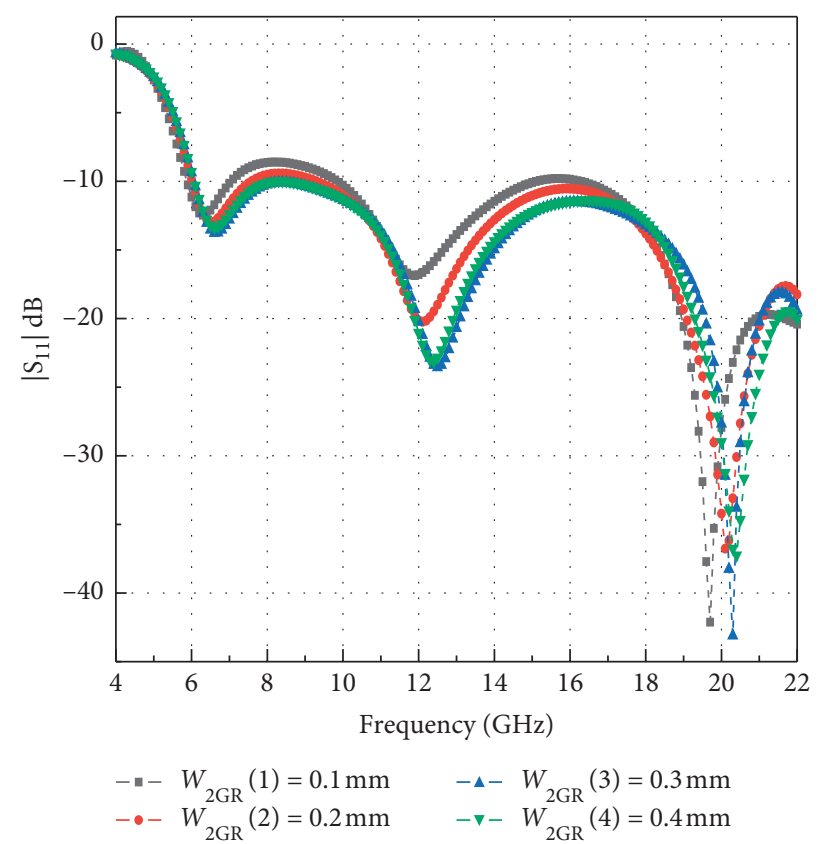

(b)

FIGURE 4: Return loss $\left|S_{11}\right|$ performance against operable frequency range: (a) effect of the width of slot line and (b) effect of the width of the groove in the taper profile.

configuration tolerances. Besides, the antenna fabricated model was fed by a practical SMA connector made of metal (causes losses due to incorrect soldering and parasitic losses in terms of capacitance and inductance). Therefore, an acceptable difference between the tested and the simulation is observed. One can control this by using efficient substrates, feeding connectors of high precision, and good quality cables to monitor performance accuracy. This slight error in the calculated results often ensures that the fabricated prototype is realized. The fabricated prototype connected with the SMA connector is shown in Figures 7(a) and 7(b) which is measured in the anechoic chamber. Furthermore, the measured and simulated return losses across operable frequency are depicted in Figure 6. It may have been observed to cover the wide $\mathrm{BW}$ from 6 to $23 \mathrm{GHz}$, that is, $(\sim 117.25 \%)$ associated with future wireless communication applications.

\subsection{Peak Realized Gain, Radiation Efficiency, and Group} Delay. This section covers the simulated and measured result analysis of the radiation efficiency, peak realized gain, and group delay. The antenna gain measures how well an antenna radiates energy in a specific direction. In contrast, radiation efficiency measures how well an antenna uses received power to emit energy in all directions. It can be observed from Figure 8 that the proposed antenna achieved the peak realized gain at its maximum value. However, due to conductor losses and reduced size due to putting a half-wave of wire into a smaller volume, the gain goes below zero for that prescribed frequency range. The interfering radiation caused by the matching network at these particular frequencies could be the cause of this gain reduction. Figure 8 shows the simulated and tested comparison of the gain and radiation efficiency of the proposed antenna. The radiation efficiency of the antenna is defined as the ratio of accepted power and radiated power. The following equation is used to calculate the measured efficiency:

$$
\eta_{\text {meas }}=\frac{G_{\text {meas }}}{D_{\text {sim }}},
$$

where $\eta_{\text {meas }}$ and $G_{\text {meas }}$ signify the fabricated prototype measured efficiency and gain, respectively, and $D_{\text {sim }}$ denotes the designed prototype simulated directivity. The excellent simulated efficiency of $95 \%$ and tested $87 \%$ is realized at the higher frequency at the operable BW. Moreover, the proposed antenna shows a gain of $3.41 \mathrm{dBi}$ at the first resonance of $6.6 \mathrm{GHz}$, the noted gain of $3.7 \mathrm{dBi}$ at $12.3 \mathrm{GHz}$, the high gain of $9.35 \mathrm{dBi}$ at $20.2 \mathrm{GHz}$ of third resonance, and the final resonance has been obtained at $22.3 \mathrm{GHz}$ with an excellent gain of $10.9 \mathrm{dBi}$. Thus, the proposed antenna received the realized gain at its peak value at multiple resonances for future wireless communication applications.

Figure 9 depicts the group delay (ns) performance parameter in the context of a time-domain analysis. It is analyzed that the proposed antenna exhibited a constant group delay of $<2$ ns across the operable frequency range, confirming that the antenna has a broadband capability.

3.3. Radiation Characteristics (E and H) Plane. The twodimensional (2D) pattern in the E- and H-planes of the proposed antenna was determined inside the anechoic 
$\operatorname{Jsurf}(\mathrm{A} / \mathrm{m})$

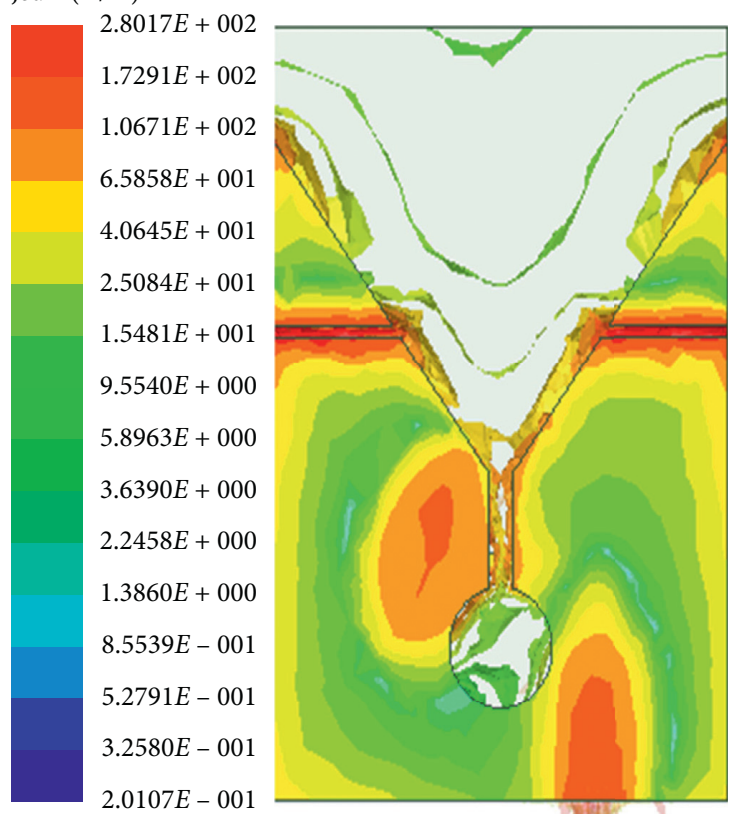

(a)

$\operatorname{Jsurf}(\mathrm{A} / \mathrm{m})$

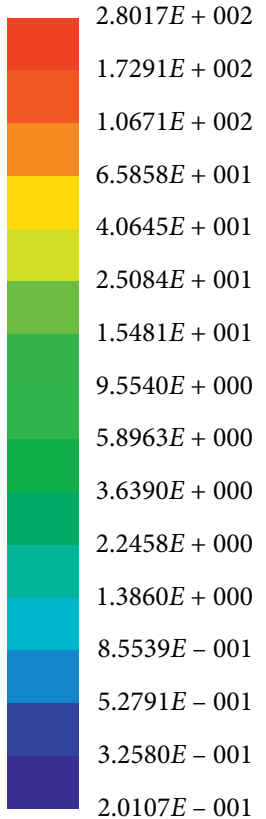

$2.0107 E-001$

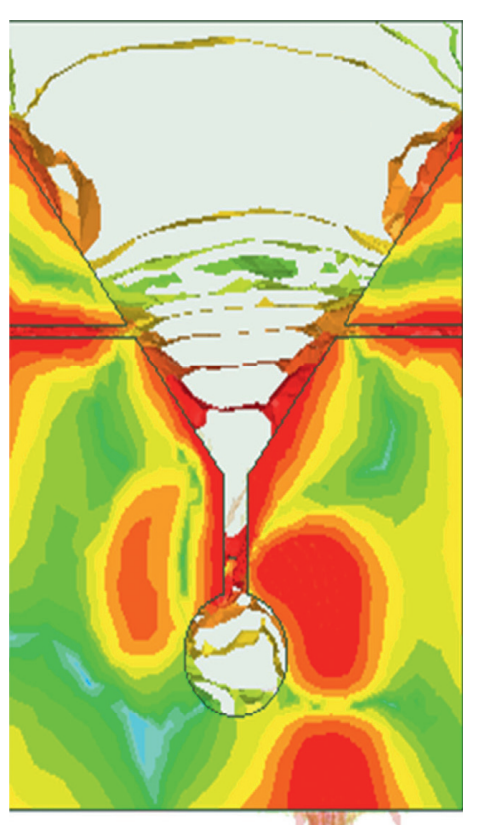

(c)
$\operatorname{Jsurf}(\mathrm{A} / \mathrm{m})$

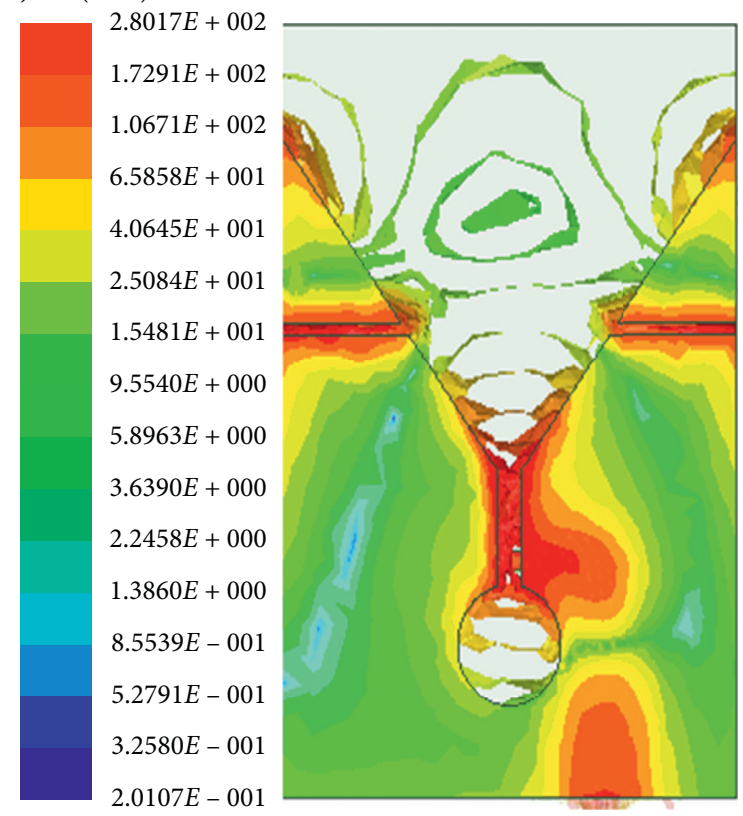

(b)

$\operatorname{Jsurf}(\mathrm{A} / \mathrm{m})$

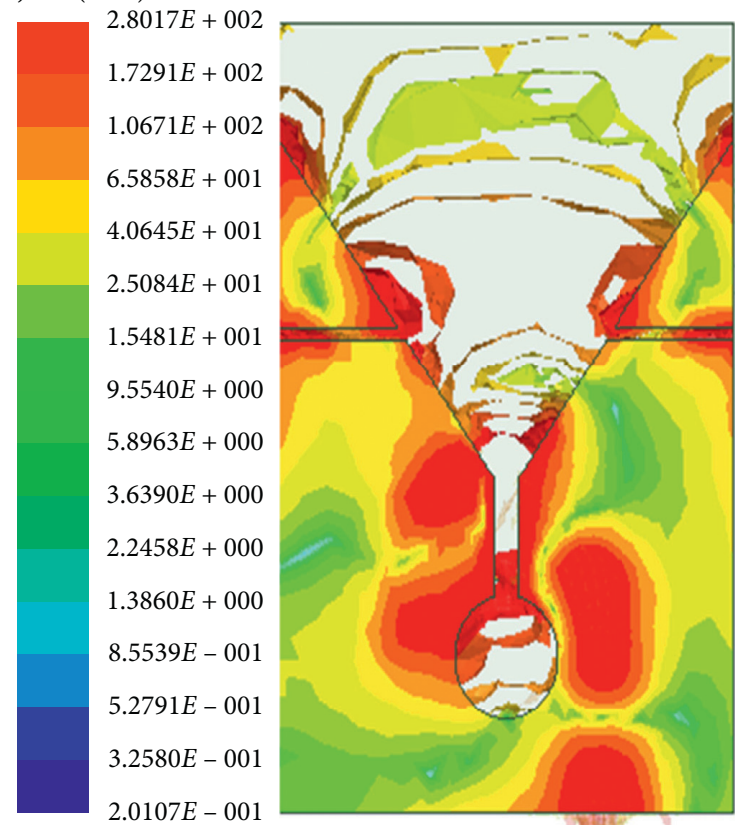

(d)

FIGURE 5: Surface current distribution at multiple resonances. (a) Resonance at $6.6 \mathrm{GHz}$. (b) Resonance at $12.3 \mathrm{GHz}$. (c) Resonance at 20.2 GHz. (d) Resonance at $22.3 \mathrm{GHz}$.

chamber room with conditions of far-field. An anechoic chamber environment and the placement of the fabricated prototype are shown in Figure 10. A cable was attached to the transmission signal anchorage of a VNA N5244A and the tunable signal generator with the standard horn antenna. Figures 11(a)-11(c) show the simulated and measured radiation patterns in the elevation E-plane $\left(\Phi=0^{\circ}\right)$ and azimuth $\mathrm{H}$-plane $\left(\Phi=90^{\circ}\right)$ at the multiple resonances. The proposed antenna exhibited stable radiation patterns at multiple resonances. As required, the E- and H-plane beam directs itself towards the $0^{\circ}$ direction. Besides, it radiates, equally in the other plane.

Similarly, results are stable to display direction around elevation plane $\Phi=0^{\circ}$ and azimuth plane $\Phi=90^{\circ}$. It is observed from Figures 11(a)-11(c) that the measured results at different resonances such as at $6.6 \mathrm{GHz}, 12.3 \mathrm{GHz}$, and 20.2 $\mathrm{GHz}$ and pattern at $0^{\circ}$ beam angle in the $\mathrm{E}$ - and $\mathrm{H}$-planes are consistent. 


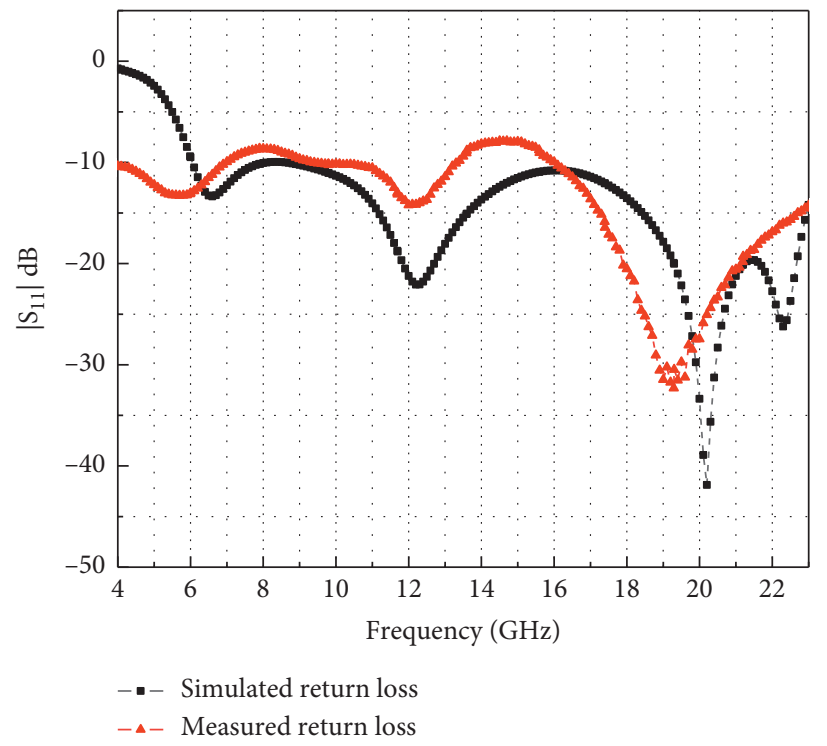

Figure 6: Simulated and measured return loss $(\mathrm{dB})$ across the operable frequency span.

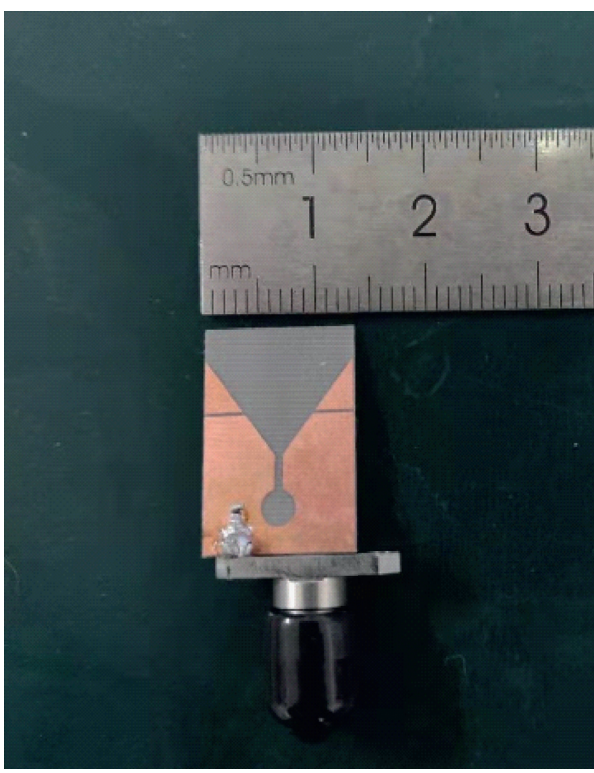

(a)

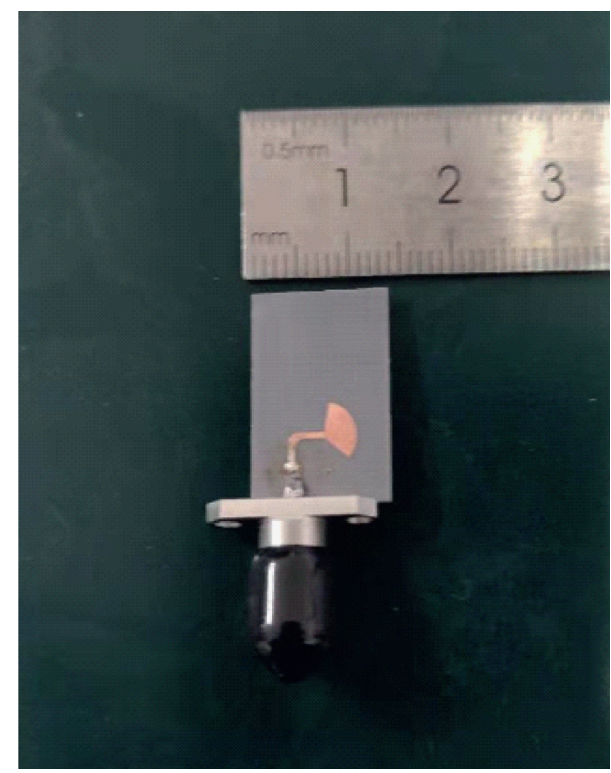

(b)

FIGURE 7: Fabricated prototype of antenna structure: (a) front view and (b) rear view.

3.4. Study of Contrasts. Table 1 provides a comparison of the antenna main features with the existing state-of-the-art work. The excellent BW and moderate gain antennas for C, $\mathrm{X}$, and $\mathrm{Ku}$ band applications were studied in $[22,30]$ that employed large space. The SIW based tapered slot antenna was investigated in [27], which occupied a large size. The presented antenna provided ample dimensions with a prolonged fabrication process and complicated assembling. Furthermore, a tapered slot array antenna for underwater communications was investigated in [26]. The presented antenna covered the microwave band of $4.0 \mathrm{GHz}-8.0 \mathrm{GHz}$ with a large physical size. In [29], a wideband loaded tapered antenna with a broad beamwidth and improved FBR was investigated. The technique used a wideband loaded three types of $\mathbb{I I}$ slots technique with plenty of space. The reported works were time-consuming and complicated. In this research, the groove technique is used, and broad BW is achieved. Due to the trade-off between the antenna key features presented and results published in the literature, it is determined that the performance analysis results would not be better than the obtained results of the antenna presented. It is concluded that the antenna's approach can produce wide BW, high gain, stable far-field patterns, and strong current flow across the tapered profile. 


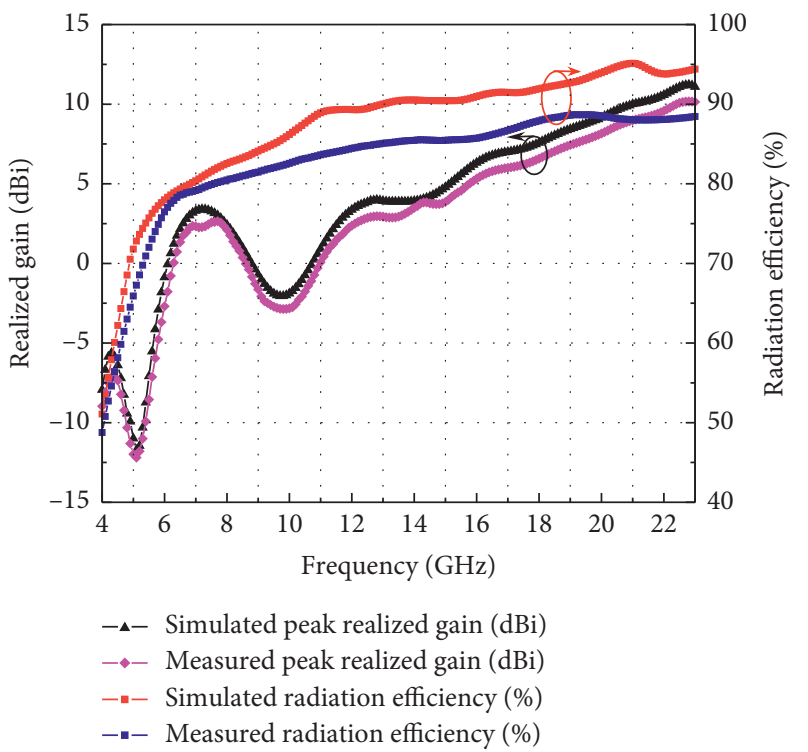

FIGURE 8: Simulated and tested peak realized gain and radiation efficiency over operable frequency span.

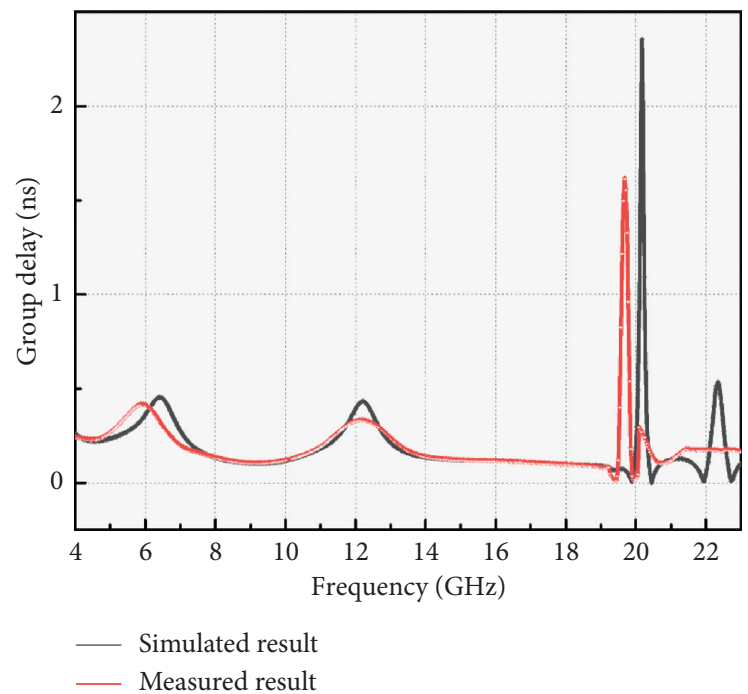

Figure 9: Simulated and measured group delay (in nanoseconds) over the operable frequency.

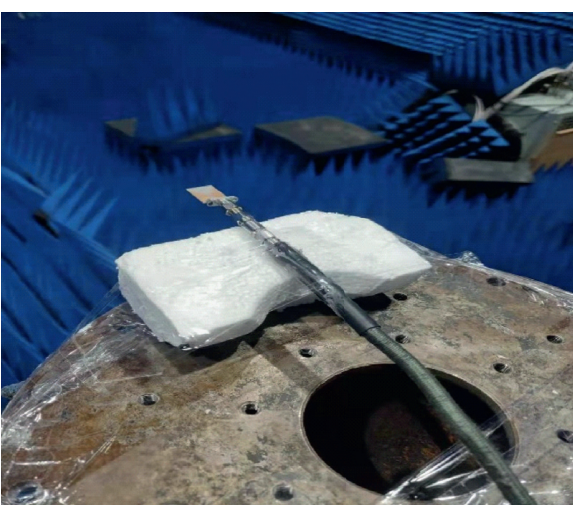

(a)

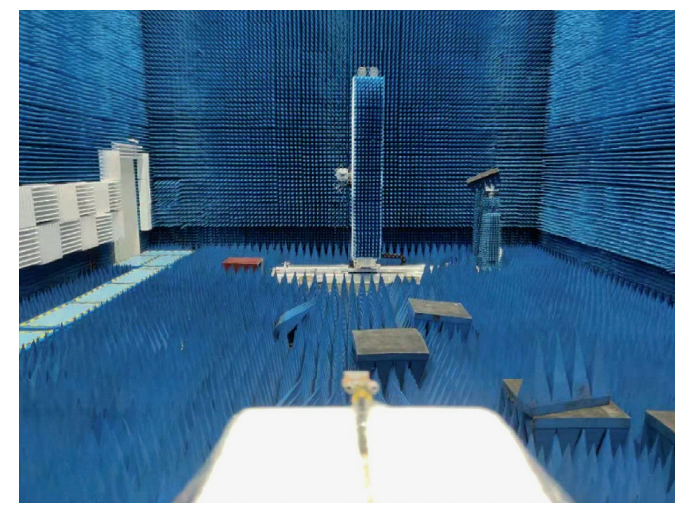

(b)

Figure 10: Antenna tested anechoic chamber environment at NJUST campus. 


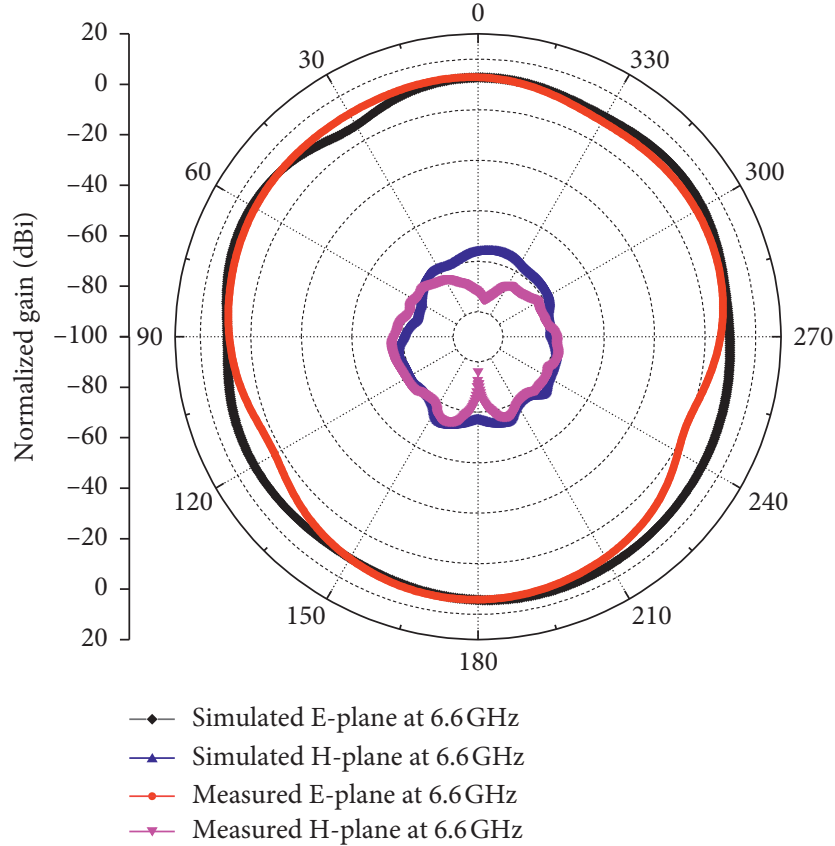

(a)

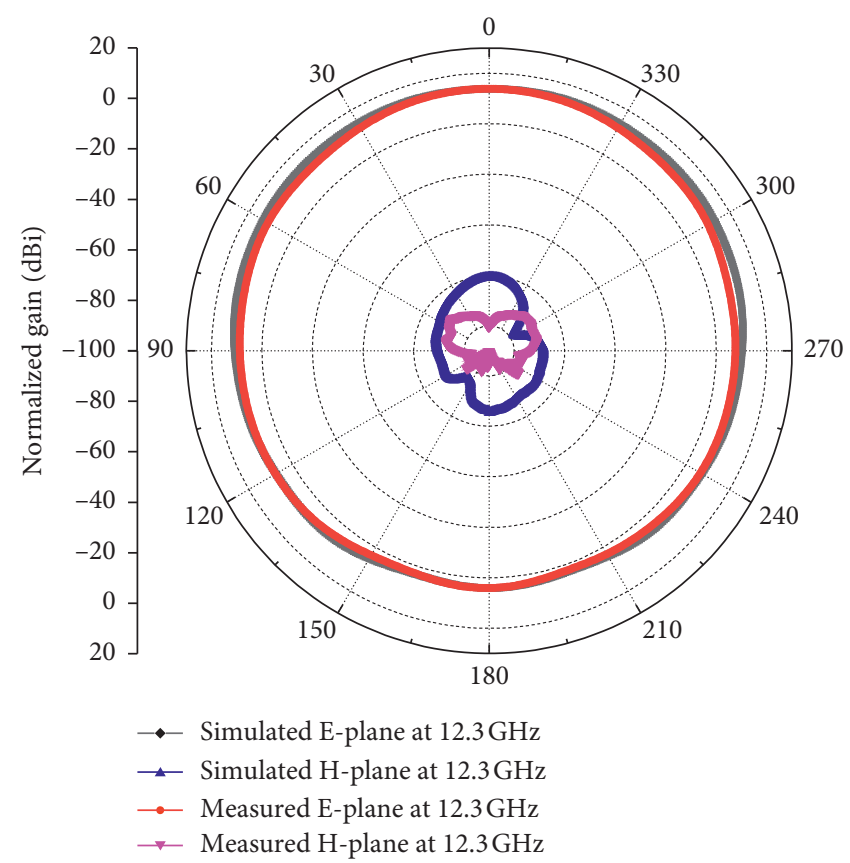

(b)

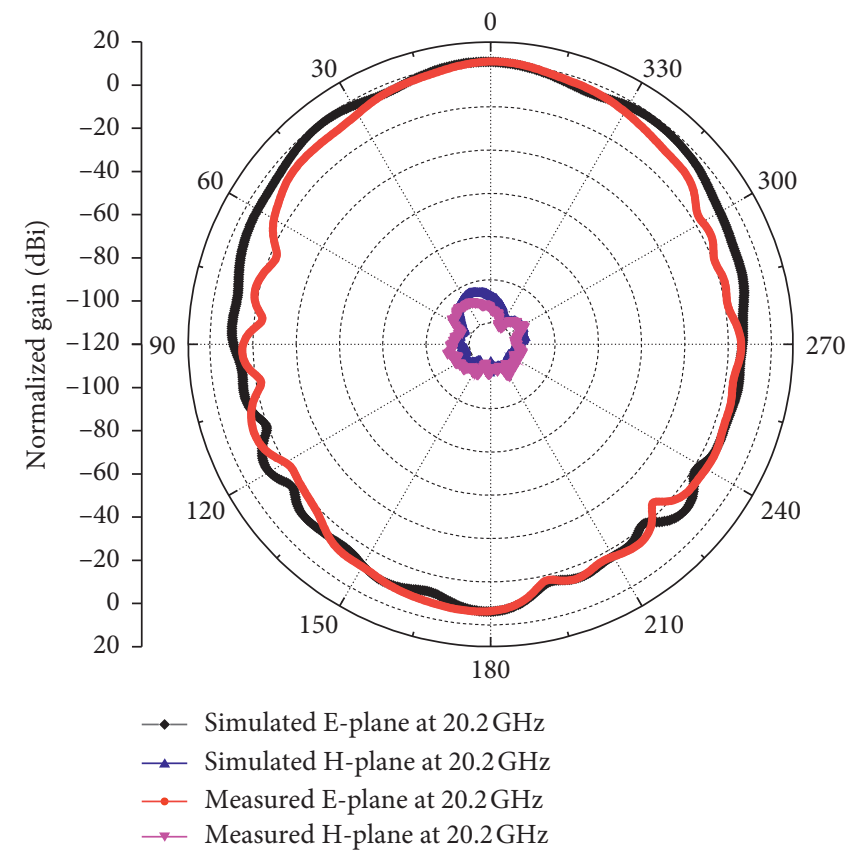

(c)

Figure 11: (a-c) Tested and simulated radiation patterns due to the E-H plane of the proposed antenna design.

\section{Conclusion}

In this paper, miniaturized broadband and high gain PVA is presented. The proposed structure comprises Teflon ${ }^{\mathrm{TM}}$ dielectric substrate, taper section, and strip line feedline with cavity stub. The feedline section is soldered with a standard $50 \Omega$ SMA connector. The single tilt groove was engraved on the top of the taper profile, which improved the proposed structure impedance BW performance. The wideband antenna possessed the compact dimension of
$0.92 \lambda_{0} \times 0.64 \lambda_{0} \times 0.03 \lambda_{0}$. The proposed antenna has been fabricated and tested in a real-time environment. The antenna exhibited a good relative impedance BW of $117.25 \%$, and the peak realized gain of $\sim 10.9 \mathrm{dBi}$ at higher resonances. Moreover, the antenna structure exhibited excellent radiation efficiency of $95 \%$ and better performance of group delay $(<2 \mathrm{~ns})$ in the time domain. Stable radiation pattern performance and vigorous current intensity of the antenna were realized at multiple resonances. Finally, the proposed antenna key characteristics have 
been compared with the recent state-of-the-art work. The designed antenna offers versatile advantages and exhibited optimal performance features making it a suitable candidate for future wireless communication applications. Besides, the proposed PVA may be further extended to wideband and high gain antenna array topology with an efficient Wilkinson power divider approach.

\section{Data Availability}

The data used to support the findings of this study are included within the article.

\section{Conflicts of Interest}

The authors declare that there are no conflicts of interest regarding the publication of this manuscript.

\section{Acknowledgments}

The authors Permanand Soothar, Dr. Hao Wang, Chunyan $\mathrm{Xu}$, and $\mathrm{Yu} \mathrm{Quan}$ greatly acknowledge the technical support and help extended by the rest of the authors in finalizing the manuscript.

\section{References}

[1] T. Saeidi, I. Ismail, W. P. Wen, A. R. H. Alhawari, and A. Mohammadi, "Ultra-wideband antennas for wireless communication applications," International Journal of Antennas and Propagation, vol. 2019, Article ID 7918765, 25 pages, 2019.

[2] C. A. Balanis, Antenna Theory: Analysis and Design, John Wiley \& Sons, Hoboken, NJ, USA, 2016.

[3] E. G. Tianang, M. A. Elmansouri, and D. S. Filipovic, "Ultrawideband lossless cavity-backed vivaldi antenna," IEEE Transactions on Antennas and Propagation, vol. 66, no. 1, pp. 115-124, 2018.

[4] R. Chandel, A. K. Gautam, and K. Rambabu, "Tapered fed compact UWB MIMO-diversity antenna with dual bandnotched characteristics," IEEE Transactions on Antennas and Propagation, vol. 66, no. 4, pp. 1677-1684, 2018.

[5] P. Shrivastava, B. T. Abe, and R. Vijay, "Substrate integrated waveguide based antipodal linear tapered slot antenna array for inter-satellite communication at $60 \mathrm{GHz}$," in Proceedings of the IEEE AFRICON, Accra, Ghana, September 2019.

[6] D. S. Woo, K. W. Kim, and H. C. Choi, "A broadband and high gain tapered slot antenna for w-band imaging array applications," International Journal of Antennas and Propagation, vol. 2014, Article ID 378527, 6 pages, 2014.

[7] Y. Xu, J. Wang, L. Ge, X. Wang, and W. Wu, "Design of a notched-band vivaldi antenna with high selectivity," IEEE Antennas and Wireless Propagation Letters, vol. 17, no. 1, pp. 62-65, 2018.

[8] X. Liu, H. Wang, B. Wu, S. Quan, J. Cao, and P. Soothar, "A novel wide bandwidth antenna design and application in wide beam scanning phased array," in Proceedings of the IEEE MTT-S International Wireless Symposium (IWS), Guangzhou, China, May 2019.

[9] H. Cheng, H. Yang, Y. Li, and Y. Chen, "A compact vivaldi antenna with artificial material lens and sidelobe suppressor for GPR applications," IEEE Access, vol. 8, pp. 64056-64063, 2020.
[10] D. Budiastuti, F. Muin, A. Gracias, A. Senjaya, and F. Y. Zukifli, "Design of CPS-FED vivaldi antenna for microdoppler radar application," in Proceedings of the TENCON 2019-2019 IEEE Region 10 Conference (TENCON), Kochi, India, October 2019.

[11] H. Oraizi and S. Jam, "Optimum design of tapered slot antenna profile," IEEE Transactions on Antennas and Propagation, vol. 51, no. 8, pp. 1987-1995, 2003.

[12] Z. A. Dayo, Q. Cao, Y. Wang, S. Ur Rahman, and P. Soothar, "A compact broadband antenna for civil and military wireless communication applications," International Journal of Advanced Computer Science and Applications, vol. 10, no. 9, pp. 39-44, 2019.

[13] Z. A. Dayo, Q. Cao, Y. Wang, P. Soothar, B. Muneer, and B. S. Chowdhry, "A compact broadband high gain antenna using slotted inverted omega shape ground plane and tuning stub loaded radiator," Wireless Personal Communications, vol. 113, no. 1, pp. 499-518, 2020.

[14] J. Guo, J. Tong, Q. Zhao, J. Jiao, J. Huo, and C. Ma, “An ultrawide band Antipodal vivaldi antenna for airborne GPR application," IEEE Geoscience and Remote Sensing Letters, vol. 16, no. 10, pp. 1560-1564, 2019.

[15] G. Hendrantoro and E. Setijadi, “Total array pattern characteristics of coplanar Vivaldi antenna in E-plane with different element width for S and C band," in Proceedings of the Progress in Electromagnetics Research Symposium-Fall (PIERS-FALL), Singapore, November 2017.

[16] P. Soothar, H. Wang, C. Xu, Z. A. Dayo, B. Muneer, and K. Kanwar, "A compact broadband and high gain tapered slot antenna with stripline feeding network for $\mathrm{H}, \mathrm{X}, \mathrm{Ku}$ and $\mathrm{K}$ band applications," International Journal of Advanced Computer Science and Applications, vol. 11, no. 7, pp. 239-244, 2020.

[17] K. Kikuta and A. Hirose, "Compact folded-fin tapered slot antenna for UWB applications," IEEE Antennas and Wireless Propagation Letters, vol. 14, pp. 1192-1195, 2015.

[18] B. Wu, H. Wang, X. Liu et al., "Optimization to the scan blindness of vivaldi array with metallic T-shaped structure," in Proceedings of the 2019 IEEE MTT-S International Wireless Symposium (IWS), Guangzhou, China, May 2019.

[19] G. K. Pandey, H. S. Singh, P. K. Bharti, A. Pandey, and M. K. Meshram, "High gain vivaldi antenna for radar and microwave imaging applications," International Journal of Signal Processing Systems, vol. 3, no. 1, pp. 35-39, 2014.

[20] J. Zhang, S.-F. Liu, F. Wang, Z. Yang, and X.-W. Shi, "A compact high-gain vivaldi antenna with improved radiation characteristics," Progress In Electromagnetics Research Letters, vol. 68, pp. 127-133, 2017.

[21] Z. A. Dayo, Q. Cao, P. Soothar, M. M. Lodro, and Y. Li, “A compact coplanar waveguide feed bow-tie slot antenna for WIMAX, C and X band applications," in Proceedings of the 2019 IEEE International Conference on Computing Electromagnetics (ICCEM), Shanghai, China, March 2019.

[22] H. N. Awl, B. A. Karim, Y. I. Abdulkarim, L. Deng, D. A. Hassan, and M. Karaaslan, "Broadband microstrip antenna for C-band, X-band, and KU-band applications," in Proceedings of the 2019 International Conference on Information and Telecommunication Technologies and Radio Electronics (UkrMiCo), Odessa, Ukraine, September 2019.

[23] F. Zhang, F. S. Zhang, C. Lin, G. Zhao, and Y. C. Jiao, "Design and parameter study of a small size tapered slot antenna," Journal of Electromagnetic Waves and Applications, vol. 23, no. 5, pp. 655-661, 2009. 
[24] A. S. Arezoomand, R.-A. Sadeghzadeh, and M. Naser-Moghadasi, "Novel techniques in tapered slot antenna for linearity phase center and gain enhancement," IEEE Antennas and Wireless Propagation Letters, vol. 16, pp. 270-273, 2017.

[25] H. Jiang, R. Shen, K. Xu, and X. Ye, "A broadband tapered slot antenna for microwave imaging application," in Proceedings of the 2017 Progress in Electromagnetics Research Symposium-Fall (PIERS-FALL), Singapore, November 2017.

[26] P. Soothar, H. Wang, B. Muneer, Z. A. Dayo, and B. S. Chowdhry, "A broadband high gain tapered slot antenna for underwater communication in microwave band," Wireless Personal Communications, vol. 116, no. 2, pp. 1025-1042, 2021.

[27] Y. Wu, K. Ding, B. Zhang, D. Wu, and J. Li, "SIW-tapered slot antenna for broadband MIMO applications," IET Microwaves, Antennas \& Propagation, vol. 12, no. 4, pp. 612-616, 2018.

[28] Z. A. Dayo, Q. Cao, Y. Wang, and P. Soothar, "A compact high gain multiband bow-tie slot antenna," in Proceedings of the 2019 International Applied Computing Electromagnetics Society Symposium-China (ACES), August 2019.

[29] Y. L. Chang, C.-Y. Cui, L. Zhang, and Y.-C. Jiao, "Design of a wideband loaded tapered slot antenna with broad beamwidth and enhanced front-to-back ratio," Microwave and Optical Technology Letters, vol. 59, no. 7, pp. 1484-1489, 2017.

[30] G. V. Krishna, B. T. P. Madhav, M. V. Giridhar, M. V. Reddiah Babu, V. Sai Krishna, and S. S. Mohan Reddy, "Bandwidth enhanced antipodal vivaldi antenna for wide band communication applications," Indian Journal of Science and Technology, vol. 9, no. 31, pp. 1-6, 2016.

[31] D. K. Naji, "Compact broadband CPW-fed taper-shaped monopole antenna with L-slots for C-band applications," International Journal of Applied Electromagnetics, vol. 3, no. 6, pp. 136-143, 2013.

[32] Z. A. Dayo, Q. Cao, Y. Wang, S. Pirbhulal, and A. H. Sodhro, "A compact high-gain coplanar waveguide-fed antenna for military RADAR applications," International Journal of Antennas and Propagation, vol. 2020, Article ID 8024101, , 2020.

[33] C. Jarufe, R. Rodriguez, V. Tapia et al., "Optimized corrugated tapered slot antenna for mm-wave applications," IEEE Transactions on Antennas and Propagation, vol. 66, no. 3, pp. 1227-1235, 2018.

[34] P. Knott and A. Bell, "Coaxially-fed tapered slot antenna," Electronics Letters, vol. 37, no. 18, pp. 1103-1104, 2001. 